\title{
Endoscopic tunneling of HeartMate II left ventricular assist device driveline
}

\author{
A. Dave Nagpal, MD, Brianne K. Larsen, PA, Nicholas G. Smedira, MD, and Edward G. Soltesz, MD, \\ Cleveland, Ohio
}

Current generation ventricular assist devices require a driveline to connect the intracorporeal device to the extracorporeal controller and batteries. Recent experience has suggested anecdotally that a longer subdermal driveline tunnel without any external velour may reduce driveline infections. To accomplish this, a long, sharp C-shaped tunneler traverses the abdominal wall blindly from the right upper quadrant to an exit site on the left upper quadrant.

We recently placed a driveline that entered the peritoneal cavity inadvertently while using the standard tunneling technique. As indications for placement of these devices expand to include sick and elderly patients, more patients will have had previous abdominal incisions and/or cachexia with little preperitoneal or subdermal adipose tissue. These factors can make blind placement of drivelines more hazardous.

Therefore, we developed a simple, cost-effective technique using our current endoscopic saphenous vein harvesting system that allows direct visualization and safe placement of the driveline. We report this experience after receiving approval from the Cleveland Clinic's institutional review board.

\section{OPERATIVE TECHNIQUE}

After median sternotomy and pump pocket dissection, a Karl Storz (Tuttlingen, Germany) 0-degree endoscopic camera with a Macquet (Wayne, NJ) blunt vein dissector tip is used to place umbilical tape no. 1 from the inferomedial pump pocket to a counterincision on the right upper lateral abdominal wall 2 to 3 fingerbreadths below the costal margin (incision 1 in Figure 1) traversing the rectus sheath. Next, the endoscope is used to place umbilical tape no. 2 immediately superficial to the anterior rectus sheath from

\footnotetext{
From the Department of Thoracic and Cardiovascular Surgery, Heart and Vascular Institute, Cleveland Clinic Foundation, Cleveland, Ohio.

Disclosures: Authors have nothing to disclose with regard to commercial support.

Received for publication April 19, 2012; revisions received Aug 1, 2012; accepted for publication Aug 16, 2012; available ahead of print Sept 14, 2012.

Address for reprints: Edward G. Soltesz, MD, Department of Thoracic and Cardiovascular Surgery, Cleveland Clinic, 9500 Euclid Ave, Cleveland, OH 44195-5108 (E-mail: soltese@ccf.org)

J Thorac Cardiovasc Surg 2013;145:297-8

$0022-5223 / \$ 36.00$

Copyright (c) 2013 by The American Association for Thoracic Surgery

http://dx.doi.org/10.1016/j.jtcvs.2012.08.040
}

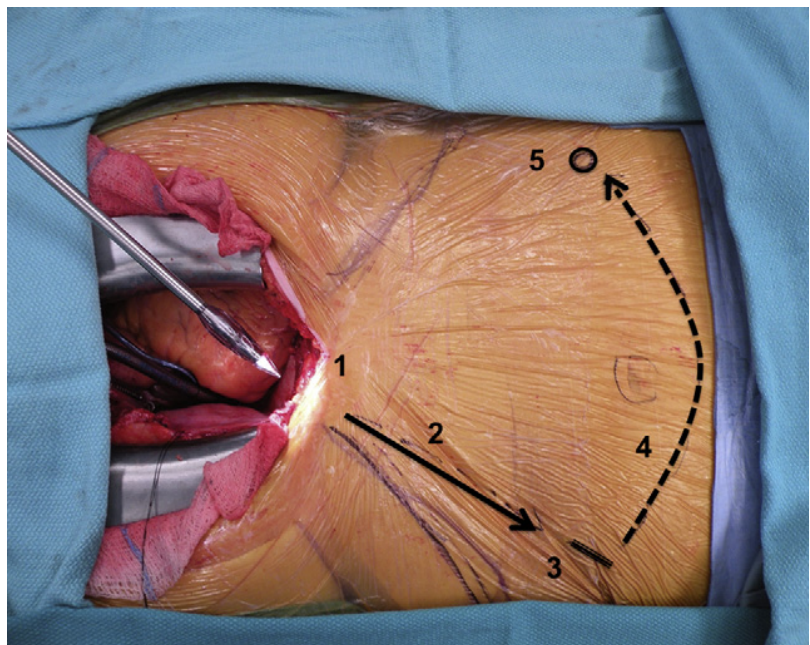

FIGURE 1. The endoscope is introduced into the inferior pump pocket (1) and then tunneled through the muscular abdominal wall (2) to the counterincision (3). After placing the umbilical tape, the endoscope is then placed into the counterincision, and tunneled across the abdomen (4), either below or above the umbilicus, to the driveline exit site (5), which is situated well above the beltline.

the counterincision to the exit site, located approximately 2 fingerbreadths below the costal margin on the lateral left abdominal wall in a location above the waist or beltline (Figure 2). Heparin is then administered.

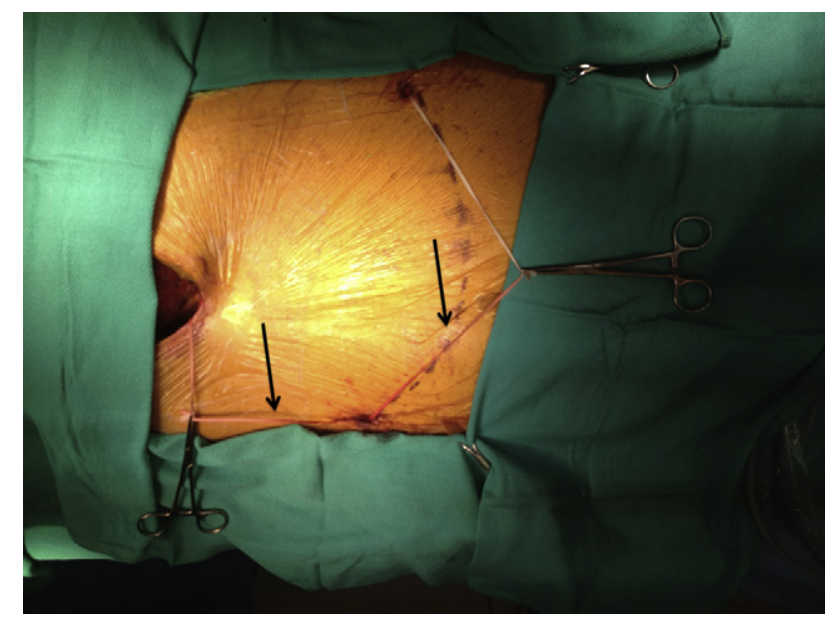

FIGURE 2. Umbilical tape is used to maintain access to the tunnel until the driveline is placed. 


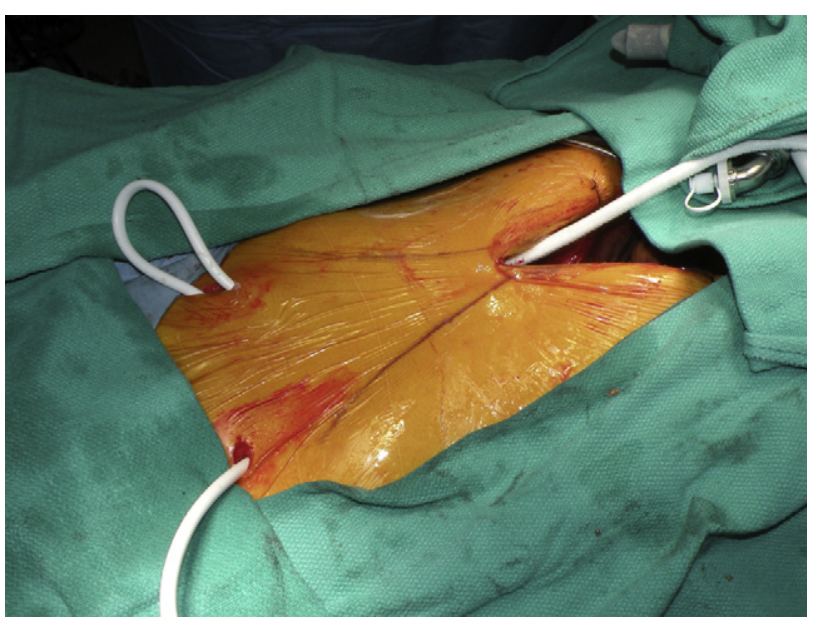

FIGURE 3. The driveline is pulled through from the pump pocket to the counterincision, then to the exit site, keeping the velour in subdermal placement.

The device is placed into the pocket, then the driveline is tied to umbilical tape no. 1 and externalized through the counterincision. The umbilical tape is then cut and discarded, and a limited length of driveline is pulled through to ensure subdermal placement of the entire velour driveline in the next step. Umbilical tape no. 2 at the counterincision is then tied to the driveline, which is then pulled along the extended suprafascial plane out through the exit site, again ensuring that the entire velour driveline remains in subdermal placement (Figure 3). The remainder of the ventricular device placement proceeds in routine fashion, as has been described in detail elsewhere. $^{1,2}$

\section{DISCUSSION}

We have now used this technique in 23 patients, and as an example of continuous quality improvement in an effort to reduce driveline-related complications, this is now our standard technique. The excellent visualization can detect when the tunnel is too deep (subrectus) or too superficial (directly subdermal) and can guide exact placement (Figure 4). For very thin patients, a tunnel through the rectus sheath may be the ideal placement. The cost of this technique is limited to the cost of the disposable blunt vein dissector tip for the endoscope. In addition, this technique can be used in

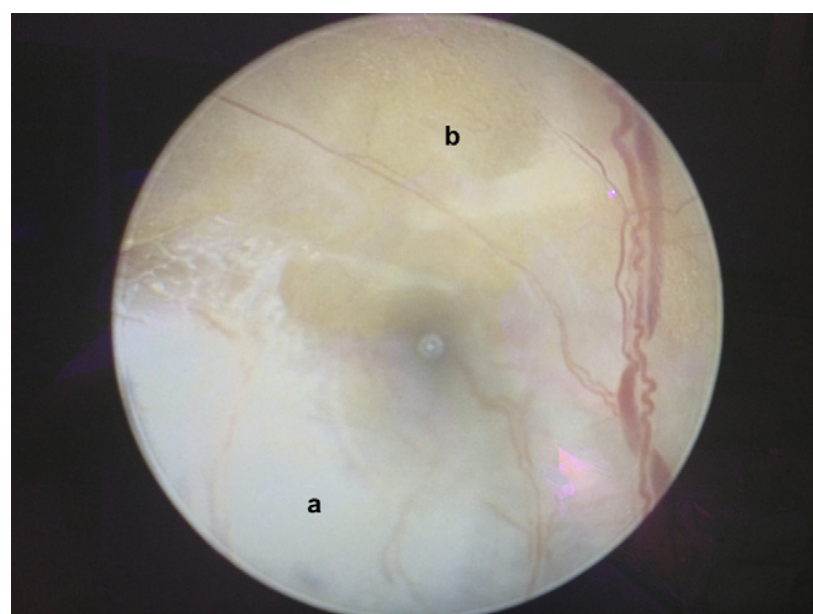

FIGURE 4. Endoscopic view of fascia ( $a$ ) and subdermal fatty tissue $(b)$ allows precise placement and avoidance of blood vessels.

patients who have driveline infections and who require redirection of the driveline or installation of a new device. The new driveline can be placed in a completely different location under direct endoscopic vision and the old driveline tunnel can be treated with vacuum-assisted closure therapy. $^{3}$

Since adopting this technique, we have not seen any early ( $\leq 8$ months of follow-up) driveline infections. In comparison, 1 of the 20 patients prior to adopting the endoscopic tunneling technique developed a Staphylococcus epidermidis driveline infection. We continue to follow these patients, and look forward to reporting longer term results of this technique.

In conclusion, this endoscopic driveline tunneling technique is a reproducible and inexpensive way to place drivelines safely and may improve the overall long-term care of patients with a left ventricular assist device.

\section{References}

1. Slaughter MS, Pagani FD, Rogers JG, Miller LW, Sun B, Russell SD, et al. Clinical management of continuous-flow left ventricular assist devices in advanced heart failure. J Heart Lung Transplant. 2010;29:S1-39.

2. Berman M, Parameshwar J, Jenkins DP, Dhital K, Lewis C, Dempster K, et al. Thoratec implantable ventricular assist device: the Papworth experience. J Thorac Cardiovasc Surg. 2010;139:466-73.

3. Schibilsky D, Benk C, Haller C, Berchtold-Herz M, Siepe M, Beyersdorf F, et al. Double tunnel technique for the LVAD driveline: improved management regarding driveline infections. J Artif Organs. 2012;15:44-8. 